\title{
Corrigendum
}

\section{Corrigendum to "A Taxonomy for Management and Optimization of Multiple Resources in Edge Computing"}

\author{
Klervie Toczé $\mathbb{D}$ and Simin Nadjm-Tehrani \\ Department of Computer and Information Science, Linköping University, Linköping, Sweden \\ Correspondence should be addressed to Klervie Toczé; klervie.tocze@liu.se
}

Received 25 November 2021; Accepted 25 November 2021; Published 15 December 2021

Copyright (C) 2021 Klervie Toczé and Simin Nadjm-Tehrani. This is an open access article distributed under the Creative Commons Attribution License, which permits unrestricted use, distribution, and reproduction in any medium, provided the original work is properly cited.

In the article titled "A Taxonomy for Management and Optimization of Multiple Resources in Edge Computing" [1], the authors have identified an error with reference [81] which should be corrected as follows [2]:

A. P. Bianzino, M. Asplund, E. J. Vergara, and S. NadjmTehrani, "Cooperative proxies: optimally trading energy and quality of service in mobile devices," Computer Networks, vol. 75, pp. 297-312, 2014.

\section{References}

[1] K. Toczé and S. Nadjm-Tehrani, “A Taxonomy for Management and Optimization of Multiple Resources in Edge Computing," Wireless Communications and Mobile Computing, vol. 2018, Article ID 7476201, 23 pages, 2018.

[2] A. P. Bianzino, M. Asplund, E. J. Vergara, and S. Nadjm-Tehrani, "Cooperative proxies: optimally trading energy and quality of service in mobile devices," Computer Networks, vol. 75, pp. 297-312, 2014. 